\title{
Procedural Justice and Management Accountability
}

As we observed in chapter 1, police systems of management accountability do not normally measure all of the outcomes that are important, and one of the outcomes that is omitted is the procedural justice with which police act in their encounters with citizens. We sought to rectify this omission, if only for a finite period of time, by administering the police services survey and summarizing results on a monthly basis at departmental Compstat meetings. With these survey-based figures, we supplemented the departments' continuing attention to crime as an outcome. The survey measures each month served both as inputs to Compstat and as the previous month's outcomes; we analyze change over time below.

We heard, albeit unsystematically at Compstat meetings, from mid-level managers-captains in Syracuse and lieutenants in Schenectady-about the efforts that they made to manage these outcomes. But we also conducted two waves of semi-structured interviews with patrol officers and patrol supervisors about what their commanders were doing to manage these dimensions of police performance. We analyze their responses to understand the managerial efforts that were made to affect officers' performance, which we discuss here, and also to understand their interpretations of the administrative priority - that is, the sense that they made of the push toward procedurally just policing, which we discuss in chapter 9 .

\section{MEASURING WHAT MATTERS}

The police services survey included numerous items on citizens' subjective experiences with police. We thought it better to present the counts of citizens' responses to specific questions-for example, whether police were polite- with which 
respondents could agree or disagree, either strongly or somewhat, rather than a summary scale like the procedural justice index (introduced in chapter 4), on the assumption that the command staff would find concrete response categories for specific survey items more readily interpretable than artificial scores on a derivative indicator, and that specific items might offer them some clues about what officers were doing and not doing that could be better managed. But we did not want to overload the command staff with information, and so we looked for a way to economize in reporting survey results. Upon compiling a baseline of survey results (seven survey waves in Schenectady and ten in Syracuse), we analyzed citizens' satisfaction in terms of process-based factors to identify those that appeared to be particularly important in citizens' overall subjective experience. From those analyses we distilled eight items that we thereupon treated as the measures around which future reporting would revolve:

- Satisfaction with treatment by police

- Satisfaction with how police handled the problem

- How helpful police were

- Whether police took care of the problem

- Whether police considered the citizen's views

- Whether the police treated the citizen with dignity and respect

- Whether police made their decision based on facts

- Whether police respected the citizen's rights

All but the fourth listed item above allowed for four categories of response, so that stronger or more intensely held views could be distinguished from less intensely held views; only whether the police took care of the problem was a binary yes/no item.

\section{Performance Measures in Compstat}

We introduced the project to the command staffs at Compstat meetings in September, 2011; the survey was under way at that time, but we did not report results then. On December 21, 2011, we appeared at the Schenectady Compstat meeting to present the summary of baseline survey findings, and to illustrate the survey items that we would be charting for them month-to-month. We summarized a larger number of items at that time, in order to place the focal items in context and explain the rationale for making those items the recurring indicators on which we would concentrate. We also broke survey results down by contact types - calls for service, stops, and arrests-and summarized the distributions on several measures of legitimacy. Our corresponding appearance at the Syracuse Compstat meeting was on January 11, 2012.

Figures 9 and 10 below are excerpts from the PowerPoint presentations at Compstat meetings. These charts are typical of those that we routinely shared at 


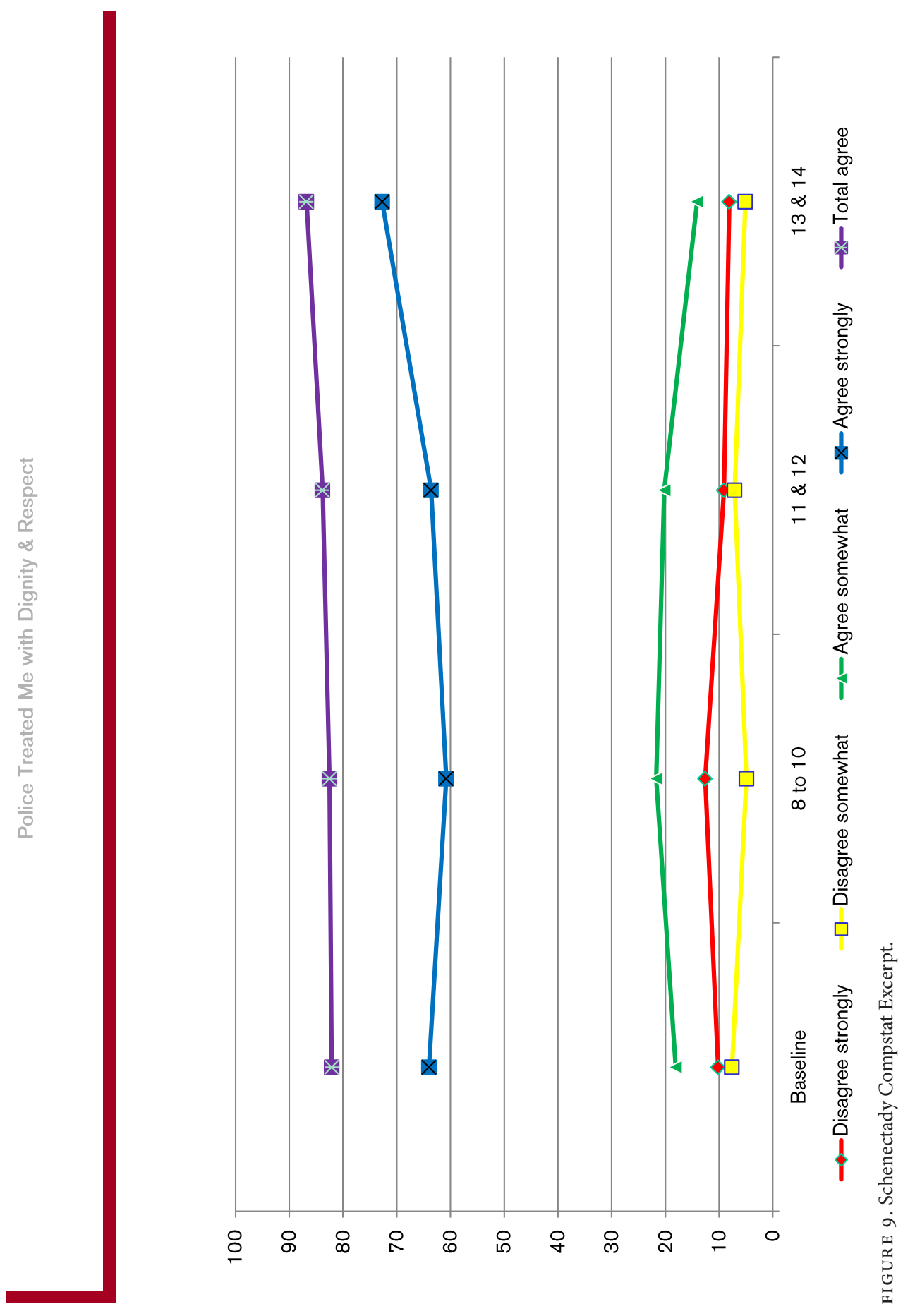




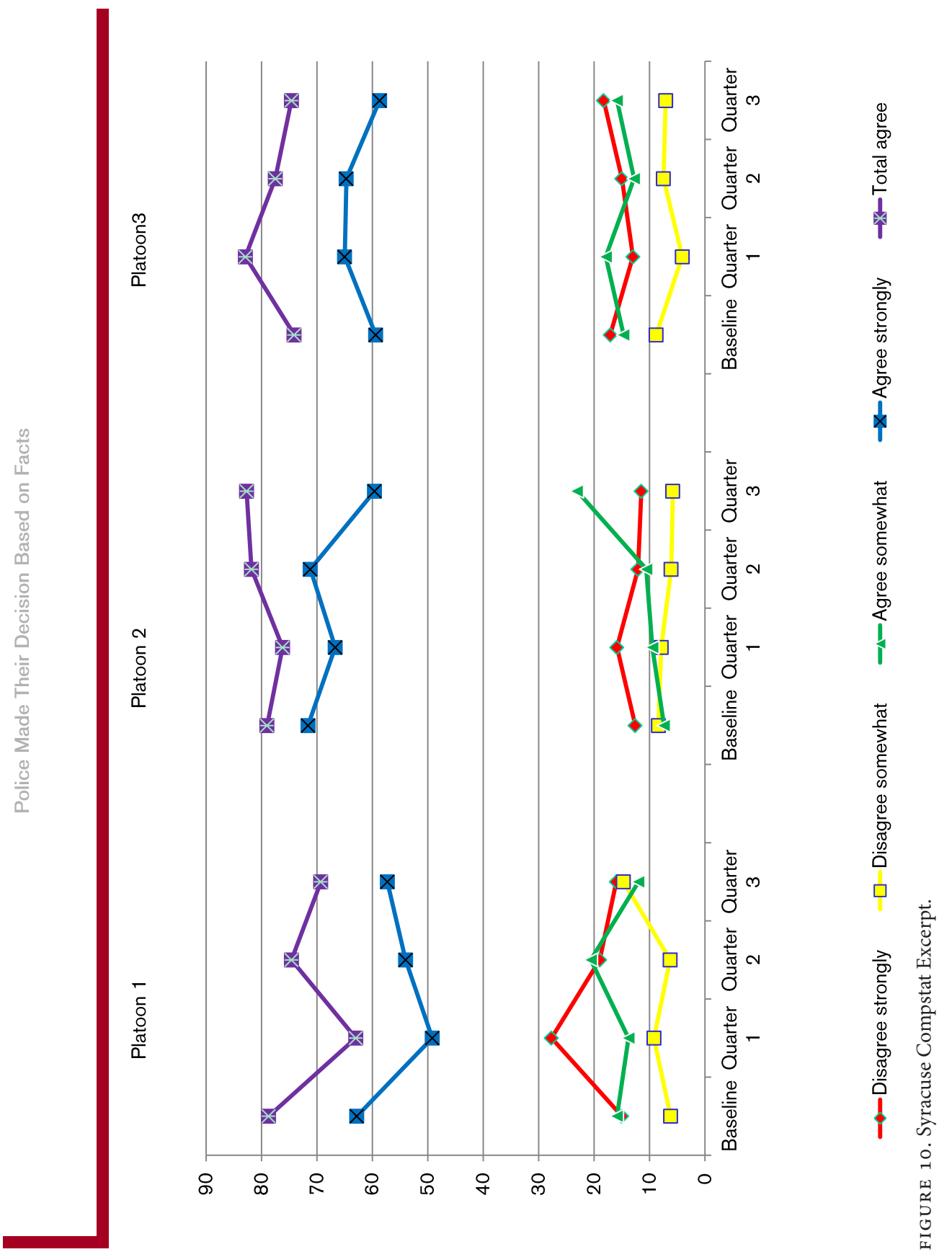


Compstat meetings; we also converted the PowerPoint slides to pdf documents and sent copies to our department liaisons. Each chart depicts the baseline levels of performance and subsequent monthly levels (labeled as survey waves).

We supplemented these routine reports with additional analyses at times. In order to provide measures of outcomes for which platoon commanders might feel a greater sense of individual responsibility, we provided for quarterly breakdowns by individual platoons, as shown in figure 10. We also undertook additional analysis as command staff raised questions about the patterns, for example, in Schenectady, we summarized the measures by patrol zone and by (CAD-recorded) response time. Both departments' command staffs expressed curiosity about how the results for their department compared to those for other cities, in response to which we shared with them the comparisons (to, e.g., Chicago) summarized in chapter 4.

\section{Interim Reports}

In addition, we prepared interim reports for each department. One report summarized survey findings in more detail than we did in Compstat meetings, based on the first twenty waves of surveys. Much as we reported in chapters 3 and 4 , we summarized findings on trust and subjective experience, and also provided breakdowns of subjective experience by contact type, call type, and patrol zone or beat. We also summarized a qualitative analysis of open-ended survey responses about the reasons for citizens' dissatisfaction, as we reported in chapter 5 .

A second report for each department was based on information gathered through interviews with patrol officers and supervisors. Detail on the interview methods is included below. The report focused on the views of the rank and file regarding the emphasis on customer service, how (if at all) expectations were being communicated down through the ranks, and potential sources of resistance to a customer-service orientation. In addition, we provided recommendations to address the barriers to efforts to manage these aspects of police performance.

\section{MANAGING WHAT'S MEASURED}

We anticipated a priori several reasons why measuring procedural justice performance would not result in detectable improvements over time. First and perhaps most basically, both of the study departments exhibited high baseline levels of subjective experience, leaving only so much room for improvement. The high baseline levels were received quite favorably by the command staffs, respectively, at the meetings at which the baseline results were reported. The Syracuse command staff, recognizing that 100 percent satisfaction was not an achievable goal, seemed satisfied that their officers were doing quite a good job of meeting citizens' expectations and treating them properly. These high levels of subjective experience, citywide, are not unique to our study departments, of course, and even without reference 
to our findings about the tenuous relationship between officers' procedural justice and citizens' subjective experience, they raise questions about how much the implementation of a procedural justice model could increase measurable subjective experience.

There are a number of other reasons to doubt that change would be observed once police managers were given measures of procedural justice performance, some of which are specific to this project. First, the measures based on the survey reflected the performance of the entire department and only occasionally that of individual platoons, which we would suppose had the effect of vitiating individual commanders' sense of personal responsibility. It was only on a quarterly basis that we could summarize the performance of individual platoons, and quarterly measures of performance are probably not sufficiently frequent to motivate managers to attend to the outcomes in question (Behn 2008). Second, everyone on the departments' command staffs was aware that the project provided for surveys that would extend over only eighteen months, and so performance measurement was a fixed-term proposition. Neither city had the funds to continue such surveying indefinitely; indeed, we are aware of no city that does (or has done) such ongoing surveys with sufficient frequency that they are useful for management accountability. The fixed-term nature of the measures of procedural justice could be expected to compromise the investment of effort that managers would make with a view to this outcome. Third, and finally, we were given the task of reporting on the procedural justice performance measures each month, which may have made it seem like an academic interlude to the Compstat meeting, and not an outcome that the departments' executive staffs embraced.

Yet another reason to be doubtful that change would be observed, and which is probably not confined to the study departments or this project, is that Compstat as executed did not stress accountability. As in Compstat mechanisms in other departments (Willis et al. 2007; Weisburd et al. 2003), platoon commanders and other unit heads did not succeed or fail by results, and we might suppose that as in other departments, Compstat was loosely coupled with street-level performance. We interviewed commanders in the study departments to learn more about current expectations of those involved in Compstat. In both departments the perception of platoon commanders was that the assessment of police performance was nearly exclusively numbers-driven (e.g., number of tickets, number of drug buys, number of field contacts, number of arrests, number of crimes). They described expectations for their role as it relates to Compstat in terms of "being on top of the numbers," "identifying patterns," and being prepared to explain during the meeting what they had done to address the patterns or numbers. While the introduction of feedback on citizens' subjective experience with police represented an additional set of numbers, interviewees did not anticipate this would have implications for how they managed their subordinates or for their role in Compstat. Most went 
on to explain that they already managed this aspect of police performance on an individual basis and they already knew the character and ability of their officers. Independently and systematically collected information (the survey) was seen as a potentially positive development insofar as it could reinforce or confirm what they already knew (akin to the purpose we see many in law enforcement attribute to crime mapping). Commanders correctly anticipated that feedback on officers' performance would not alter expectations for their role in Compstat. In neither department was Compstat used to hold commanders accountable for achieving results in the ends of policing (crime reduction, disorder control, or improvements in the quality of life), and it was not a mechanism for holding commanders accountable for improvements in outcomes measured through the survey. We seldom heard administrators ask unit commanders to explain what steps they had pursued to manage and promote procedurally just policing.

All of these obstacles to the management of street-level procedural justice arguably pale by comparison to the larger structural obstacles in American police departments. As Michael Brown observes, "police administrators and supervisors are caught between demands for loyalty to the men on the street and demands from the public that police power be used in a specific way or even curtailed" $(1981,91)$. On the street, police work is performed in an environment marked by uncertainty, ambiguity, and danger, in the face of which officers cope by pulling together. Administrators must depend on officers to perform this arduous work satisfactorily, and as Brown points out, "the pressures for loyalty and solidarity are refracted throughout the police bureaucracy" (90), with norms that prohibit second-guessing and micromanagement.

The implementation of community policing in Chicago hit a cultural "wall" whose foundation is set on these structural conditions. Wesley Skogan $(2006,81)$ describes the reluctance of police officers to perform tasks that are seen as not "real police work," and also their "aversion to civilians playing any role in telling them what to do or evaluating their performance." Officers do not believe that anyone who has not done police work can understand it, and they tend to dismiss police administrators who introduce change as "out of touch" with the street (also see Skogan 2008).

The intrinsic demands of the work on the street and of cultural norms probably account for the limited success of training that is geared toward shaping how officers relate to police clientele. In her study of the effects of a recruit training curriculum into which the concepts and skills of community and problem-oriented policing had been integrated, Robin Haarr (2001) found positive changes in recruits' attitudes, which subsequently dissipated as the new officers went into the field and were exposed to the work and to cultural norms. More to the point of the procedural justice model, the Quality Interaction Training Program of the Chicago police had limited and mixed effects in the context of the academy (Schuck 
and Rosenbaum 2011; Rosenbaum and Lawrence n.d.), and modest effects in its in-service form (Skogan et al. 2014); we might expect that even these effects would decay over time without consistent reinforcement. Many departments have offered training in "verbal judo," and although we are aware of no empirical evaluations of the impacts of such training, anecdotal evidence suggests that it is not always well-received by officers. The content of training along these lines- "quality interaction" or "verbal judo" - is for many officers not compatible with the multiple and conflicting demands of the work as they experience it. ${ }^{1}$

Managerial options are, then, limited. Platoon and other unit commanders could exhort their officers, directly and indirectly through first-line supervisors, to be more mindful of the utility and propriety of interacting with citizens with procedural justice. They could explain the benefits in the form of citizen compliance with police direction and citizen cooperation, as well as the standing of the department with the community. Armed with information on citizens' subjective experience, they could reinforce the exhortation with measures of police performance. Ultimately, however, the efficacy of such exhortation turns on the sense that supervisors and officers make of commanders' expectations.

Commanders and supervisors could engage in greater direct oversight of officers' interactions with citizens. This takes time, of course, and moreover, it carries other risks. Violating the norm of not second-guessing the judgments of the officer who is handling a situation, direct oversight risks antagonizing officers and undermining the routine, day-to-day cooperation of subordinates in performing basic police tasks. Schenectady supervisors are expected to routinely complete a Service Quality Control Report (SQCR) as a means of exercising oversight over the quality of interactions between officers and citizens. This practice did not appear to be resisted by supervisors or to be objectionable to officers. We suspect this could be because sergeants did not appear to use them as a means to prove that an officer had done something wrong or to show them how they might do something better (which would violate the norm of not second-guessing officers' judgments), and the occasions on which officers were the subject of a report were few (policy calls for four SQCRs per sergeant, per month).

Administrators have some additional options. In-service training could be offered. Indeed, Schenectady planned to make procedural justice the subject of inservice training in the fall of 2012, but those tentative plans were derailed when the assistant chief of the Field Services Bureau sustained an injury and was out of work for some time. Syracuse contemplated a podcast by the chief to be played at roll calls. As we recounted above, however, the content of training and exhortation is filtered through officers' understanding of the requirements of their work.

Still other administrative options for managing street-level procedural justice are administrative rule-making and early intervention systems. Rules could be promulgated-for example, rules that require officers to explain to those whom 
they stop the reason(s) for the stops, and to give citizens an opportunity to explain themselves. As we explained in chapter 2, however, the capacity of police administrators to enforce such rules is directly proportional to the visibility of the conduct to which the rules apply, and the procedural justice of officers' actions is of decidedly low visibility. Early intervention systems could be structured to flag repeated citizen complaints about discourtesy and other forms of procedural injustice, but citizen complaints are of dubious validity as indicators of procedural injustice, and early intervention takes the forms of either training or counseling, whose impacts on officers' performance depend on the sense that officers make of the content.

\section{Patrol Interviews}

We conducted interviews with patrol sergeants and patrol officers in order to assess the views of the rank and file regarding the emphasis on customer service, how (if at all) administrative expectations were reverberating down through the ranks, and any sources of resistance to a customer-service orientation. In our conversations with uniformed personnel, we did not use the term "procedural justice," which would likely not have been recognized by or meaningful to them. Instead, we framed "customer service" and "citizen satisfaction" with police performance as the topic of the interviews. In retrospect, the term "customer" may have set a less neutral tone for the interviews than, say, "citizens' assessment of the quality of police service" or "the quality of police citizen interactions" might have done. However, we and the command staff used the term "customer service" from the outset of the project, and so the use of that term during the interviews was consistent with prior practice.

Two waves of interviews were conducted in each department, the first in June 2012, after five to six months of survey feedback to command staff, and the second in February 2014, well after the final feedback. We asked sergeants what, if anything, they and their platoon or unit commander had done to direct officers' attention to the importance of customer service. In addition, we asked patrol officers what, if anything, their field supervisors had done to direct attention to the importance of customer service. The structured interview protocol also assessed perceptions of the extent to which customer service is an organizational priority, how officers' performance in terms of customer service was measured, awareness of the ongoing surveying of citizens, and the extent to which respondents felt citizen input was an appropriate means to monitor police performance. We conducted a total of eighty-seven interviews with patrol sergeants and patrol officers in the study departments: fourteen and eleven sergeants in Syracuse and Schenectady, respectively; thirty-one patrol officers in each department. We did not detect meaningful differences in the nature of the responses between waves 1 and 2 . The wave 2 instruments paralleled wave 1, with the exception of a question to determine whether the respondent had been interviewed during the earlier 
wave (seven respondents indicated they were interviewed two times and two were uncertain). For the most part we did not detect a difference in managerial styles between the two departments, so we combine responses, and highlight the exceptions to this rule of interdepartmental congruence.

\section{THE MANAGEMENT CONTINUUM}

The presumption guiding our work was that police legitimacy can be enhanced when measures of relevant performance are made available to managers. Of course, simply making the information available is insufficient; managers must believe they are accountable for managing performance and must take steps to communicate the chiefs' expectations and their own expectations to their subordinates. We identified three patterns that formed a management continuum. Supervisors who did nothing fell at one end of the spectrum, and those who seemed to routinely address the importance of customer service at the other; supervisors whose approach was best characterized as intermittently directing attention to customer service fell in the middle. See figure 11.

\section{Supervisors' Responses}

In both departments, very few respondents stated that either they or their commander were not communicating expectations about the importance of procedural justice as an outcome for which their subordinates were responsible. The few individuals who did not direct attention to customer service either ignored the departments' push to stress procedurally just policing or more actively spoke against it. For example, when asked what if anything they had told their subordinates about the importance of customer service, we heard responses such as: "I tell them officer safety is the goal, not customer service"; "It is kind of difficult. I can't go to every call and hold their hand."

Supervisors whose efforts were intermittent reported mentioning that patrol should do its best to "be respectful" or "watch your tone" when handling calls, or "try" to emphasize customer service "when possible." "It's hard to tell adults [patrol officers] what to do. But I say things like don't swear and treat people with respect. Even if you think it is ridiculous you need to listen and don't curse." Their efforts generally reflected a commonsense approach, because their own expectations were very straightforward. Most of them presumed that reinforcing these statements at roll call every so often was sufficient, with only a subset going on to hold officers accountable by reviewing the feedback we provided each month or observing officers on calls and using concrete examples to reinforce their directives.

Most respondents reported making a regular effort to direct attention to the importance of customer service. Generally, this included sharing the information that was disseminated at Compsat meetings and mentioning the importance of 


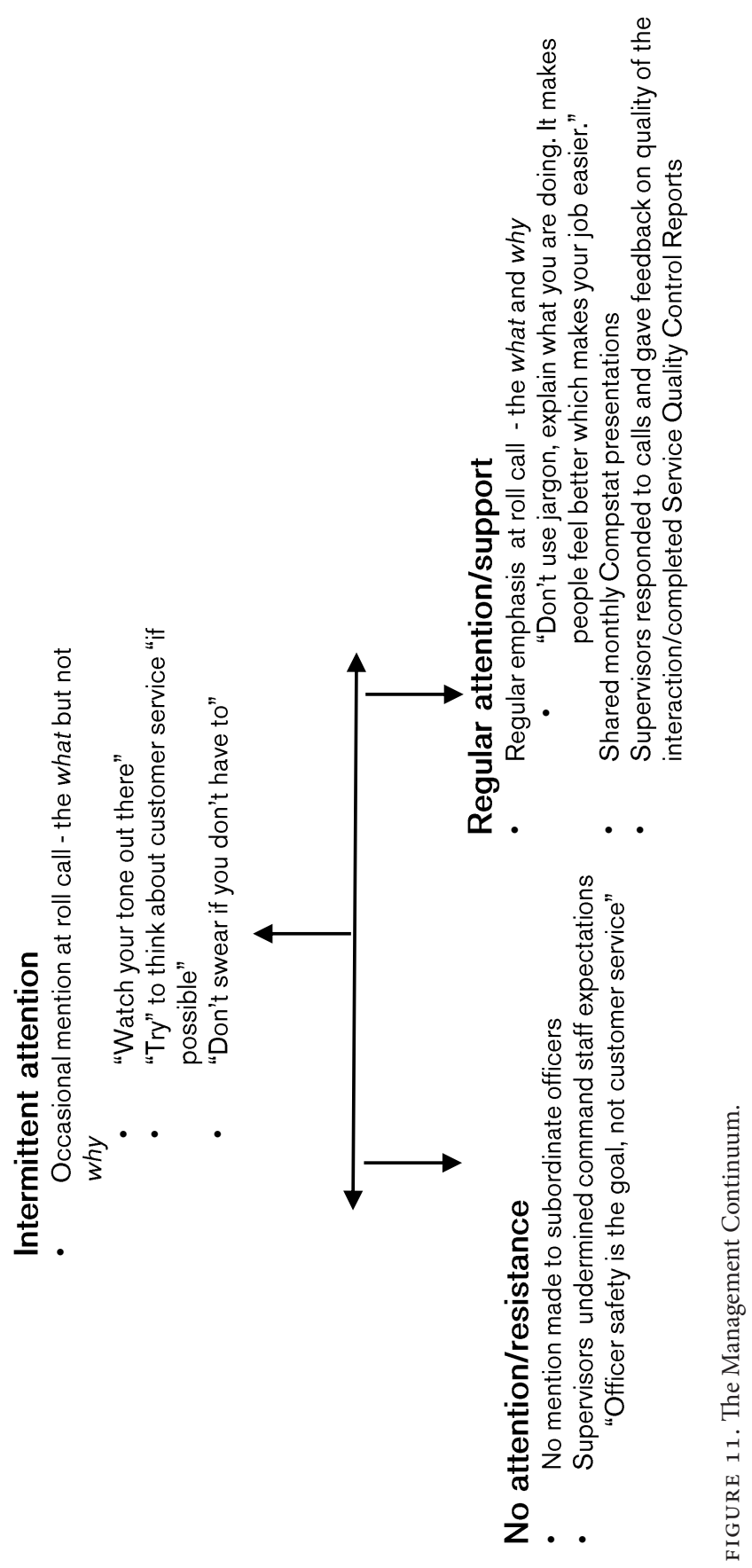


customer service during line-up or roll call. In Schenectady, the importance of regularly completing Service Quality Control Reports (SQCR) was emphasized as a means to routinely direct attention to customer service. Among those who routinely stressed the importance of customer service at line-up or roll call, three basic messages were delivered. One was the message that customer service was important to command staff, so, like it or not, patrol needed to go along with it. While the supervisor did not personally support the emphasis-and made that clear-s/he was still going to monitor subordinates' performance in these terms because they recognized that their own performance turned on platoon-level measures of customer satisfaction. The second message communicated was that customer service was important, but without reference to why it was important. The final message delivered by managers was that customer service was a priority to command staff and to the field supervisor. In addition, these supervisors differed from others in that they seemed also to articulate to their subordinates why it was important:

"The better you are with customer service the less frustrated you will be on the street."

"I tell them it isn't a big change from what they do now. They just need to be clear with what they are doing, don't use jargon, and explain why you are doing what you are doing. It makes people feel better, which makes your job easier."

"I’ve spoken to officers saying talk to people don't demand things. When you treat someone like an ass you'll end up fighting with them."

For the most part, the message communicated to officers by supervisors who regularly drew attention to the importance of customer service mirrored that of those who only intermittently addressed this dimension of police performance. Most managers explained that it is part of a supervisor's job to monitor officer behavior, so they routinely reminded their officers to "be courteous" or "explain what's happening." "Treat those you treat as if they were family." You "treat them like your mom should be treated." Supervisors who connected positive interactions with citizens and improved outcomes for officers were in the minority.

We detected one meaningful difference between the two sites in what supervisors emphasized when discussing customer service. Managers in Syracuse were more likely than Schenectady supervisors were to frame their discussion of customer service in terms of monitoring, responding to, and directing subordinates to avoid citizen complaints. This emphasis was also apparent in officers' descriptions of steps supervisors had taken to manage this dimension of police performance.

Among those who framed supervisory efforts to enhance customer service in terms of citizen complaints, supervisors either did so privately on an individual basis or they addressed the individual officer and also drew lessons from the incident-level to bring to the platoon. Some supervisors did express their view that citizens should be treated with dignity and respect, and that when they were not, the result would be a justified complaint. We contrast supervisors who acknowledged 
the appropriateness of citizens expecting quality treatment with those supervisors who did not focus on what citizens should rightfully expect. These supervisors focused on officers and managers and the value to them in avoiding the attention brought on by complaints.

The responses below characterize the responses of supervisors who focused on citizen complaints as the avenue for enhancing the quality of police interactions. When asked what, if anything, they had done to communicate their expectations of how subordinates should treat citizens to subordinates, we heard the following:

"If people get complaints, we handle them and do what we should. We don't want young guys treating people poorly. We hold them accountable."

"Even if the complaint is unfounded, follow up with officers on how they could have handled it better so there would not have been a complaint. A lot of complaints are that the officer was rude, etc., not polite."

"Nothing per se. We have a system in place where at the sergeant-level, if a citizen has a complaint with an officer we address it."

"We make sure individual complaints are taken care of."

"When we have issues that we hear or see we'll bring them up at roll call and explain the issues related to the complaints."

"Handle complaints if we get them ... don't want anybody looking at the platoon poorly, so will get angry sometimes."

While the content of (valid) citizen complaints overlaps somewhat with procedurally unjust policing, complaints represent only the tip of the proverbial customer disservice iceberg, and moreover, high-quality police service in the form of procedurally just performance is not equivalent to action that provides no grounds for complaint. In the typical U.S. city, complaints are filed in a small fraction of the incidents in which citizens believe that police have acted improperly, and even when valid complaints are filed and thoroughly investigated, evidentiary constraints often forestall administrative action in individual cases. Furthermore, and perhaps more important, procedurally just policing is more than taking no actions that are complaint-worthy. We return to this below.

\section{Patrol Officers' Responses}

We also asked patrol officers what, if anything, their field supervisors did to direct their attention to the importance of customer service. Their responses corroborated supervisors' descriptions. Patrol responses supported the three management styles described above and shown in figure 11. Managers whom we describe as taking no steps to direct attention to customer service were described by their subordinates as doing "nothing" or "nothing really." Intermittent efforts were described by officers in the following ways:

"I've heard them say watch your attitudes with people. No swearing. Do what you have to, but don't lose your cool right away." 
"Mention it occasionally. Just mention it to us on heated calls. Not all people are super nice all the time, and cops are people."

"He touches on it once in a while. He tells us not to yell and swear if you don't have to."

"Been times at line up, reminders to be courteous and watch language."

"Once in a while they might bring it up. No lecture every day."

"Every now and again they reinstate [sic] the fact they want us to figure out the call and 'leave everyone happy."

Officers whose descriptions of field supervisors' management style suggested routine efforts to direct attention to customer service made comments such as:

"Roll call training and [the supervisor] brings it up in general conversation to remain professional, regardless of other person's demeanor."

"Reminds us of how important it is to be courteous to people. Reminds us to act appropriately."

"Supervisors regularly go over calls, review calls. They show up on-site and afterwards they give us feedback. They are making sure we are being professional and getting back to people."

"We are made aware of the surveys. Supervisors regularly show up on calls and give us regular reviews."

"They tell us: 'We have an image to uphold, remember to follow the policy, and don't use excessive force. Remember, you are always being watched.' They [supervisors] are always reminding us. They do a good job of reminding us."

Again, in Syracuse in particular, monitoring performance in terms of customer service was perceived by many officers as a primarily reactive, initiated by management only in response to a civilian complaint. In officers' own words, it was:

"More reactive than proactive. But that is the nature of the beast."

"Always stress not to get civilian complaints."

"Address when there is a complaint and what you can do better."

"Hands-off attitude unless there is a complaint."

"Only when there is a complaint."

"I don't know. If there is a complaint they address it and explain how to properly handle the call if they don't like what they did."

In our observations and interviews, we did not sense strong efforts to actively undermine the administration's desire to inculcate a customer-service orientation within the departments. To be sure, some managers felt that the customer-service emphasis was inappropriate, and these individuals tended to frame the administration's emphasis as reflecting a deliberate choice to prioritize citizens' needs over officers'.

\section{IMPACT OF MEASURING PERFORMANCE}

Schenectady command staff first saw a report of the survey-based performance measures at the Compstat meeting of December 21, 2011. If we think 
of the initiation of procedural justice performance measurement as an intervention or treatment, then the first post-intervention contacts in Schenectady would have been in the latter half of December or perhaps the first half of January (survey wave 11 or 12). Since the corresponding meeting in Syracuse was on January 11, 2012, the first post-intervention contacts in Syracuse would have been in the latter half of January (wave 13).

\section{Subjective Experience}

Given the fairly weak connections between officers' procedural justice and citizens' subjective experience, we would expect little or no detectable change in the procedural justice index, based on the police services survey data, over time. We would therefore expect that even very effective efforts on the parts of platoon commanders and others would be manifested in only small and perhaps undetectable changes at the margins in citizens' subjective experience. The survey items each provide for a rough calibration of citizens' perceptions, with arguably greater differentiation when they are combined, but even so, the procedural justice index is limited in the differences that it can capture. Moreover, a sample size of fifty per wave or even a hundred per month limits our capacity to distinguish real (but small) change from sampling error.

Analyzed as monthly means over time, the procedural justice index fluctuated between 6 and 10, with few exceptions. The post-intervention mean was somewhat higher than the pre-intervention mean in Schenectady, though that reflected one spike that began prior to the intervention and another toward the end of surveying, and somewhat lower in Syracuse.

A simple comparison of pre- and post-intervention means takes no account of other factors that affect subjective experience, and whose effects would not necessarily even out over time. Using the same preliminary model of subjective experience that we presented in chapter 4 , therefore, we estimated the difference in subjective experiences that followed the initiation of measuring performance in the context of a regression model. We add a linear trend variable and a nonlinear trend variable to the models to account for temporal variation other than that attributable to the initiation of measurement.

The regression results (details of which can be found in Worden and McLean 2016) by and large replicate what appeared as month-to-month fluctuation. Schenectady exhibits a modest (but statistically insignificant) increase in overall subjective experience in the post-intervention period, while a negligible difference can be seen in Syracuse. Across all three platoons together in each department, no improvement over time can be detected. Allowing the pre-/post-intervention difference to vary across the three platoons, there is some evidence that different platoons followed different trajectories, but only in one case (that of Syracuse's platoon 3 ) is the difference large enough to be statistically significant. The addition of the controls for the characteristics of individual incidents provides a similarly 
mixed set of estimated changes over time, none of which is statistically significant. Estimated changes in Syracuse are not all in the same direction, though none of them can be reliably differentiated from zero.

\section{Observed Police Behavior}

Observational measures of officers' procedural justice and injustice much more directly tap the outcomes that we might expect police managers could affect. The timing of the observations, which were done after the survey, meant that the measures based on observational data could not be incorporated into Compstat reporting of procedural justice performance measures. But insofar as managerial efforts were made to improve these outcomes, we might expect to find evidence of it in the observation-based measures of officers' procedural justice and injustice. The pre-intervention levels of procedural justice fluctuated between 6.4 and 7.5, with an overall mean of 7.0, while the post-intervention means fluctuate between 6.2 and 7.7, with an overall mean of 7.0. Procedural injustice varies between 0.3 and 1.3, with pre- and post-intervention means of slightly over or under 0.7 .

When we take into account any possible trends over time and the other factors that we included in the models of procedural justice and injustice in chapter 7 , we find only one meaningful difference in the post-intervention period on either measure: procedural justice improved on platoon 3 subsequent to the introduction of measuring citizens' subjective experience. No reliable difference can be detected on the other platoons or in the measure of procedural injustice. See Worden and McLean 2016.

From the interviews with patrol officers and supervisors on Schenectady's platoon 3, we gather that routine efforts were made to direct attention to the importance of procedurally just policing. Sergeants indicated that the platoon commander generally followed up with them to share the survey results after the monthly Compstat meeting. Following that, either they or the lieutenant would share this information at line-ups following the Compstat meeting, in addition to routinely issuing general reminders to officers to be mindful of the way they interacted with citizens. Officers' descriptions of their supervisors' efforts to manage police performance in these terms corroborated this management style. Some supervisors on the other platoons described themselves, and were described by their subordinates, as taking some of the same steps, but we did not detect as much platoon-level consistency in the management approach. And that is an important point: it would probably not be sufficient for the platoon commander to draw subordinates' attention to the virtues of procedural justice (or "customer service"); all or most of the first-line supervisors would also need to be on board, and it appears that in the case of Schenectady's platoon 3, they may have been on board. 


\section{SUMMARY}

Measuring procedural justice performance did not generally result in detectable improvements over time. Despite the fact that the administration's push to make departments more customer-service-oriented was a top-down initiative, developed without input from rank and file, and included civilians in defining the latter's performance-two conditions often associated with thwarted efforts to promote change-we did not sense that overt resistance played a meaningful role in limiting improvements over time. Several factors may explain why broad improvements in performance were not detectable, none of which we presume to be confined to the study departments. First and most simply, both the study departments began with high baseline levels of subjective experience, leaving little room for improvement. Furthermore, monthly measures of police performance were injected into Compstat mechanisms that, as in other police departments, do not heavily emphasize accountability. And of utmost importance, even had managers directed more attention to this aspect of police performance than they previously had, our data suggest that what officers do and do not do is only weakly related to subjective experience. In the case of one of Schenectady's platoons, however, whose commander and supervisors all gave the quality of police-citizen interactions regular attention and also drew connections to valued outcomes, officers' procedural justice improved at the margin.

In addition, and despite our efforts to explain concepts, the idea of procedurally just policing was ambiguous for many officers and supervisors, and their efforts to make sense of the concept and the implications it represented for their daily work may have colored both the extent to which managers embraced more actively managing this aspect of police performance and the extent to which officers altered their behavior in meaningful ways. To this we turn in chapter 9. 